\title{
AN IMPROVED CWT-BASED ISLANDING DETECTION METHOD FOR A DEVELOPED MICROGRID IN REAL-TIME
}

\author{
*Alper YILMAZ, Department of Electrical and Electronics Engineering, Bursa Technical University, Turkey, \\ alper.yilmaz@btu.edu.tr \\ (iD) https://orcid.org/0000-0003-3736-3668) \\ Gökay BAYRAK, Department of Electrical and Electronics Engineering, Bursa Technical University, Turkey, \\ gokay.bayrak@btu.edu.tr \\ https://orcid.org/0000-0002-5136-0829)
}

Received: 03.12.2019, Accepted: 21.04.2020

Research Article

*Corresponding author DOI: $10.22531 /$ muglajsci.654432

\begin{abstract}
The island mode operation problem is a significant event of deterioration in a power system, and this fault must be detected in the fastest and most accurate way for the reliable operation of the microgrid structure. Recently, numerous islanding detection methods based on signal processing have been proposed in the literature. In this study, an improved, continuous wavelet transform (CWT)-based islanding detection method is proposed for microgrids. Island mode conditions are investigated in the developed PV-based microgrid connected to a low voltage grid. The proposed method uses only the voltage signal on the point of common coupling (PCC). A series of discrete values are selected for scales and shifts of continuous wavelets and then CWT is applied for PCC voltage. In this way, the computational load is minimized. This method has many advantages comparing to conventional methods and has been tested in real-time for a PV-based microgrid prototype. The results show that the developed CWT-based islanding detection method can detect different types of island modes in the developed microgrid. Besides, the islanding detection time of the proposed method varies between 105-110 ms in any island mode operations, and it is faster than the conventional detection methods. None detection zone (NDZ) is also almost zero in the proposed method. Thus, the CWT-based islanding detection method provides both a reliable NDZ and a short detection time for microgrid applications.
\end{abstract}

Keywords: Island mode detection, Continuous wavelet transform, Microgrids, Automatic fault detection

\section{MİKROŞEBEKELER İÇIN GERÇEK ZAMANLI CWT-TABANLI GELIŞTİRÍLMİ̧ ADA MOD TESPITT YÖNTEMI}

\section{Özet}

Ada mod çalışma problemi, bir güç sistemi için önemli bir bozulma olayıdır ve mikro şebeke yapısının güvenilir bir şekilde işletilmesi için bu arızanın en hızlı ve en doğru şekilde tespit edilmesi gerekir. Son zamanlarda, sinyal işleme tabanlı çok sayıda çalışma önerilmiştir. Ancak bu çalışmalar modelleme ve benzetim çalışmaları ile sınırlı kalmıştır. Bu çalışmada, mikro şebekeler için gerçek zamanlı, geliştirilmiş sürekli dalgacık dönüşümü (CWT)-tabanlı ada mod tespit yöntemi önerilmiştir. Ada mod koşulları, alçak gerilim şebekesine bağlı fotovoltaik (FV)-temelli mikroşebeke için araştırılırmıştır. Önerilen yöntem sadece ortak bağlantı noktası (OBN) gerilim sinyalini kullanmaktadır. Sürekli dalgacıkların ölçekleri ve kaymaları için bir dizi ayrık değer seçilmiş ve daha sonra PCC gerilim sinyaline CWT uygulanmıştır. Bu sayede hesaplama yükü en aza indirilmiştir. Geleneksel yöntemlere göre çok sayıda avantaj barındıran bu yöntem, gerçek zamanlı olarak laboratuvar koşullarında FV-temelli mikro-şebeke prototipi için test edilmiştir. Sonuçlar, uygulanan otomatik CWTtemelli ada mod tespit yönteminin geliştirilen mikro şebekede farklı ada mod koşulunu yüksek doğrulukta tespit edebildiğini göstermektedir. Önerilen yöntemin ada mod tespit süresi, herhangi bir ada modu operasyonunda $105-110$ ms arasında değişmekte olup, geleneksel yöntemlerden daha hızlıdır. Ayrıca önerilen yöntemde, algılama dışı bölge (ADB) minimum seviyededir. Sonuçta, CWT-temelli ada mod tespit yöntemi hem güvenilir bir ADB hem de mikro-şebeke uygulamaları için kısa süreli bir tespit sağlamaktadır.

Anahtar Kelimeler: Ada mod tespiti, Sürekli dalgacık dönüşümü, Mikro-șebeke, Otomatik arıza tespiti

Cite

Yılmaz, A., Bayrak, G. (2020). "An improved cwt-based islanding detection method for a developed microgrid in realtime," Mugla Journal of Science and Technology, 6(0), 10-17. 


\section{Introduction}

Integrating distributed generation systems to the grid is a critical issue in maintaining the power system's stability and reliability. IEEE 929-2000 standards [1] define circuit breaker trip times for different voltage and frequency values to ensure system safety and sustainability in case of any fault in the connection point (point of common coupling (PCC)) in microgrids. In the absence of any protection, the distributed generation units will continue to feed the load even in the event of a fault condition [17]. Therefore, fast and accurate detection of island mode is important for human and system security [2].

Island mode operation is the case that when a distribution system is electrically isolated from the rest of the power system, the energy flow is maintained by the distributed generation system currently connected to it [3]. The grid-connected photovoltaic (PV) system continues to supply the load even though it is disconnected from the grid in island mode operation. As a result, the power system and the distributed generation unit can be damaged in this case. It is also vital for personnel working in the power system [4]. In the case of unintended island mode operation in this system, there is serious damage to both the distributed generation unit and the operator [5]. It is of the highest importance that island mode detection is performed as soon as possible and with the proper accuracy.

Islanding detection methods (IDMs) can be examined under 3 headings as remote, local, and intelligent methods. Local IDMs are grouped as passive, active, and hybrid methods. Active and passive IDMs are defined as inverter embedded methods, and these methods are the most widely used detection methods. The reliability of passive methods is not particularly sufficient for systems with distributed generators since these methods have a large non-detection zone (NDZ). Active methods contain noise depending on the signal injected into the system, and these methods also have NDZ. The NDZ, which should be as small as possible, in the inverter-embedded methods depends on the local load [6]. Therefore, if the system is in a balance of power, such methods cannot be effectively detected island mode [7]. Advanced inverter-independent passive methods based on signal processing presented in the literature to eliminate the disadvantages of these methods.

Numerous methods based on signal processing have been proposed for islanding condition detection in the literature. Signal processing-based IDMs can utilize the time-frequency components of a signal, which is an important advantage over other detection methods. Fourier transform (FT), Wavelet transform (WT), TT (time-time)-transform, s-transform, and Hilbert-Huang transform are basic signal processing-based methods proposed for the detection islanding condition [8]. The FT method is missing time information. This method cannot be used to detect all disturbance conditions. Although this shortcoming has been overcome by the development of the short-term FT method, it is inadequate since it is unable to analyze both low and high-frequency components of the islanding condition signal with the fixed scale used in the windowing process [9].

The WT method can locally investigate discontinuities in high-level derivatives and sudden changes in signals where other signal processing methods are insufficient to detect islanding conditions. Besides, the ability to examine the signal in different frequency bands is an important advantage of this method. Numerous methods have been proposed for islanding detection with WT. In one of these studies [10], the WT-based method proposed for island mode detection was applied to asynchronous generator type wind turbines. The proposed method was tested under different load conditions, and island mode detection was performed in less than 0.2 seconds according to the determined threshold values. In [11], a discrete wavelet transform (DWT)-based voltage sag and voltage swell detection method using $\mathrm{db} 2$ and db8 mother wavelets is proposed. The performance of the proposed method is compared with conventional disturbance detection methods. In another study [12], the DWT-based fault detection method was proposed for distributed generation based on hydrogen energy. In the referenced paper [18] sparse s transform-based IDM proposed and IDM tested different islanding and non-islanding conditions. This method detects islanding conditions in 22 ms. Time-frequency based islanding detection method proposed in [19] for distributed power generation systems. The results obtained from simulation and experimental studies are compared with the results obtained from the methods in the literature. Voltage sag/swell, island mode faults, and power quality disturbances signals were investigated and classified by the proposed method. The paper referred to in [13] presented a real-time un-decimated wavelet transform (UWT)-based islanding and power quality disturbance detection method for PV-based microgrids for the first time. A new continuous wavelet transform (CWT)-based IDM for grid-connected distributed generators was proposed in [14], and noise suppression is also applied when there is a high level of noise. The proposed method has been tested for different types of failures in the MATLAB/Simulink environment and proved to be reliable.

In this study, island mode conditions in a PV-based microgrid connected to the low voltage grid from the PCC are investigated, and a real-time CWT-based IDM is proposed. Only the voltage signal at the PCC is used when performing this method and a set of discrete values is selected for the scales and shifts of continuous wavelets, and then CWT is applied. Thus, none detection zone (NDZ) is also almost zero in the proposed method. After applying the CWT to the voltage signal in the CWT- 
based IDM, the squares of the obtained coefficients are calculated. In the last stage, the coefficients are accumulated on the scale and islanding detection is performed according to the threshold value of cumulation determined by standards [1]. Computational load and measurement time loss are minimized by this method that will provide an advantage in real-time applications. The proposed method was tested in realtime for a prototype of a PV-based microgrid. The results show that the applied CWT-based IDM can detect different types of island modes. Besides, the islanding detection time of the proposed method varies between 105-110 ms in any island mode operations, and it is faster than the conventional detection methods.

\section{Continuous Wavelet Transform (CWT)}

The wavelet transform (WT) method, which has been frequently used in pattern recognition applications and fault detection methods in recent years and laid by $A$. Haar [15]. WT is a signal processing method capable of processing data at different scales and resolutions.

The WT method uses a scalable window concept called mother wavelet $(\psi(\mathrm{x}))$, which is different from the constant windowing concept used in STFT. $\left(\psi_{s, b}\right)$ is determined using Equation (1)

$$
\psi_{s, b}=\frac{1}{\sqrt{s}} \psi\left(\frac{t-b}{s}\right)
$$

The main wavelets are finite, asymmetrical, and irregular, unlike the sinus sign in the FT method. To be called a wavelet function, the integral of the function must be zero, and the integral of the square of the same function must be one [15].

The conditions for the mother wavelet are specified in equations (2) and (3).

$$
\begin{aligned}
& \int_{-\infty}^{\infty} \psi(t) d t=0 \\
& \int_{-\infty}^{\infty} \psi^{2}(t) d t=1
\end{aligned}
$$

Daubechies wavelet $(\mathrm{dbN})$ type found by Ingrid Daubechies is the most common type for disturbances and fault detection methods. In this study, the db8 wavelet given in Fig. 1 is used because of its characteristic and low processing load.

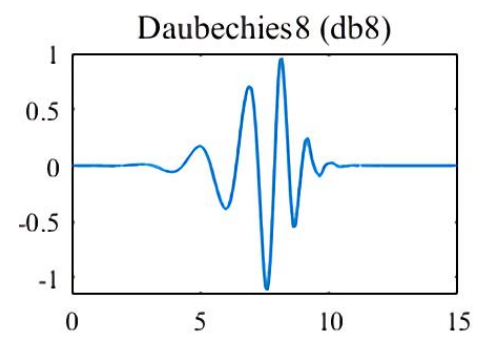

Figure 1. Daubechies8 mother wavelet type
Continuous wavelet transform (CWT) is obtained by multiplying the shifted wavelet function by the scaling amount for the whole time [16]. The multiplication results in a large number of wavelet coefficients. The SDD coefficients of the signal are determined as in Equation (4) by using the wavelet function.

$$
C W T(s, b)=\frac{1}{\sqrt{s}} \int_{-\infty}^{\infty} f(t) \psi\left(\frac{t-b}{s}\right) \mathrm{dt}
$$

where $\mathrm{f}(\mathrm{t})$ is the signal. In Equation (4), (b) represents the shift factor, and (s) represents the scaling factor. The shift parameter (b) shifts to the right if it is greater than zero and to the left if it is less than zero.

Most of the real-world signals you encounter are available as discrete-time examples, and there is no closed-form solution of Equation (4) integration. Therefore, in the study, a set of discrete values is selected for the scales and shifts of continuous wavelets, and then CWT is applied [16].

When applying the CWT to a signal, the main wavelet is shifted along the time axis, depending on the offset value. For each shift, the coefficient of similarity between the mother wavelet and the signal is calculated. After the coefficient finding process is continued until the entire signal is covered, the wavelet scale is changed, and the same steps are repeated for each scale value.

\section{Proposed CWT-based Automatic Islanding Detection Method}

In this part of the study, the proposed CWT-based islanding detection method is introduced in detail. The flow chart of the proposed method is given in Fig. 2. The developed algorithm is performed in the LabVIEW environment.

The algorithm process starts by receiving the voltage signal at the point of common coupling (PCC) with the help of an electronic measurement card and data acquisition (DAQ) card. The voltage signal is decomposed, and the coefficients are obtained with the developed program in the LabVIEW. Unlike other methods, after applying the CWT to the voltage signal in the CWT-based IDM, the squares of the obtained coefficients are calculated, and a scalogram (waveletpower spectrum) graph is plotted. The coefficients are accumulated on the scale axis to determine the peak value at the time of fault to understand the moment of occurrence of the fault. In the last stage, islanding detection is performed according to the threshold values determined by international standards. 


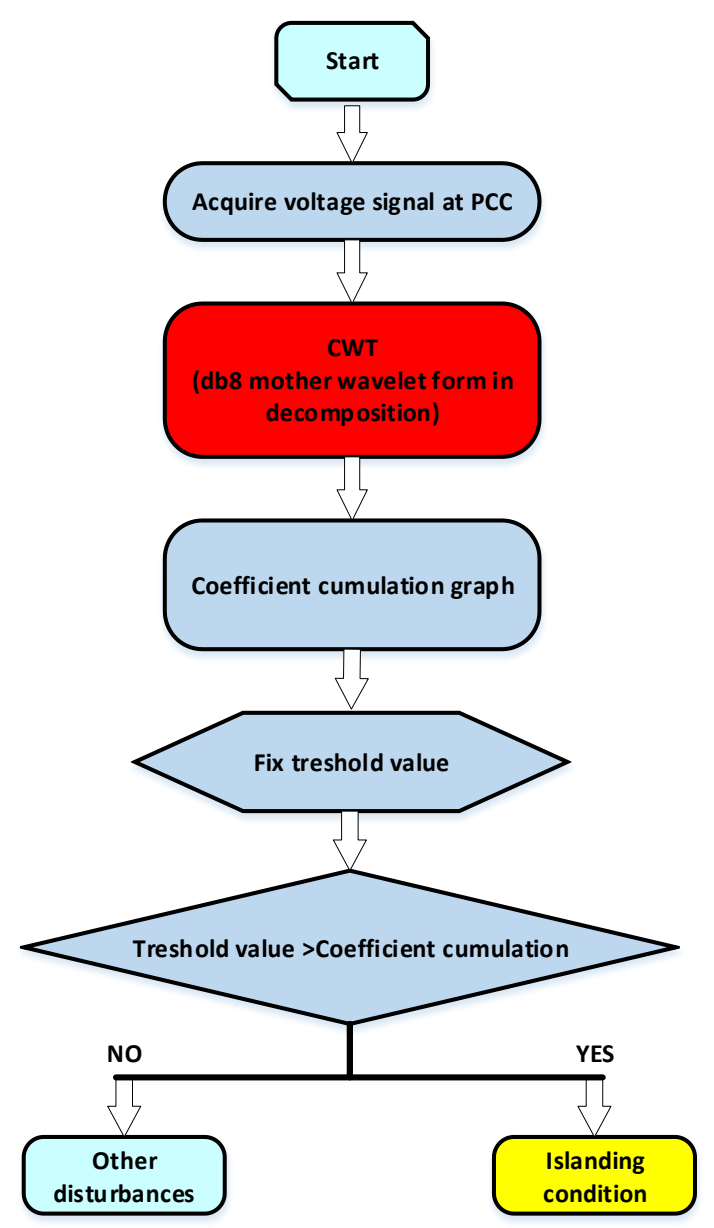

Figure 2. Proposed CWT-based automatic islanding detection method

\subsection{Studied PV-based Microgrid Test System}

The proposed CWT-based islanding detection method was tested on the prototype PV-based microgrid. The test system is indicated in Fig. 3a. The test system is located in the Bursa Technical University smart grid laboratory, and it consists of series of 6 Jiangyin HR200Wp-24V PV modules, an SMA Sunny boy $1300 \mathrm{Wp}$ inverter, an electronic measurement card, a DAQ card, a PC with LabVIEW software and parallel RLC load.

In the test system, the output of the PV array in the laboratory is connected to the full-bridge inverter. The inverter provides grid synchronization and maximum power point tracking. The inverter structure has an $\mathrm{H} 5$ topology developed by SMA. The efficiency of inverter $96.0 \%$. The switching frequency is variable depending on the situation and more than $10 \mathrm{kHz}$. The inverter output is filtered and connected to the grid via a circuit breaker (CB). In the study, solid-state relays (SSRs) resistant to $40 \mathrm{~A}$ peak current is used as $\mathrm{CB}$. The PCC has a parallel RLC load $(\mathrm{R}=100-\mathrm{ohm}, \mathrm{L}=0.13 \mathrm{H}$ and $\mathrm{C}=0.08$ $\mathrm{mF}$ ). The system resonance frequency and quality factor are 2.5 and $50 \mathrm{~Hz}$, respectively. This condition can be considered the worst-case scenario to detect islanding conditions according to IEEE 929-2000 standards.
The voltage signal information obtained by the electronic measurement and data acquisition card in the PCC is transmitted to the computer where the LabVIEW program is installed to perform the signal processing step. Fig. 3b shows this structure. LV28P-type voltage sensor and LA 55-P type current sensor are used to observe the grid voltage and current, respectively. The decomposition is applied to the voltage signal using the CWT-method, and the coefficients are determined.

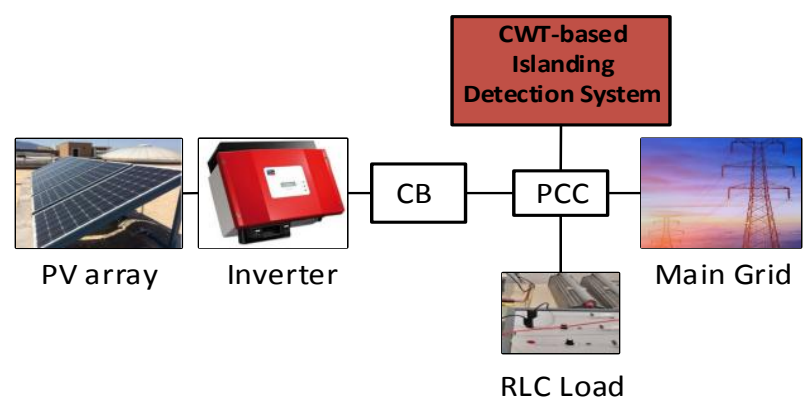

(a)

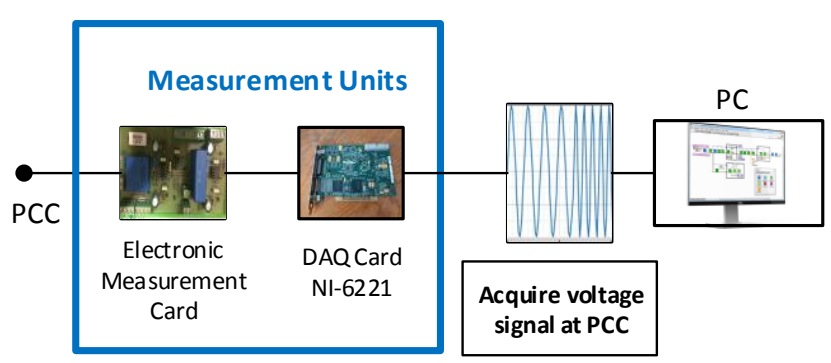

(b)

Figure 3. The studied microgrid system

The developed prototype PV-based microgrid system is operated under the different grid, and load conditions. The grid frequency is $50 \mathrm{~Hz}$, and the sampling frequency of the grid voltage is selected as $1 \mathrm{kHz}$. The proposed method uses the db8 wavelet. It uses the data obtained from the test system to determine wavelet selection and sampling frequency.

\subsection{Real-Time Implementation of the Proposed IDM}

Fig. 4 shows the block diagram of the program realized with LabVIEW. The data measured from the PCC point is acquired with the DAQ card and then transmitted to the computer with developed software installed for further processing. DAQ MX USB-6221 type signal processing card is used in the system. 


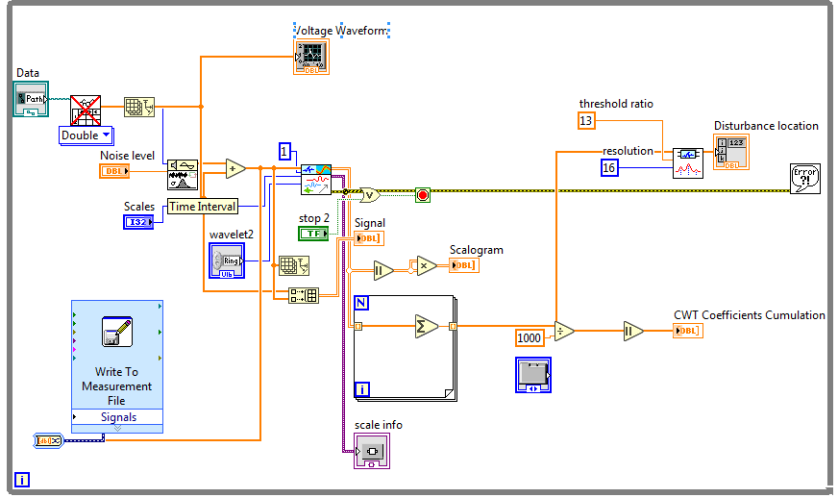

Figure 4. The developed software for CWT-based IDM

The data transferred to the LabVIEW program can be tracked through the LabVIEW interface in real-time. These data can be recorded periodically using LabVIEW related tools to analyze the changes occurring at the time of the event. The interface program for the improved CWT-based IDM is given in Fig. 5. Wavelet type, coefficient selection, and scaling settings can be set via this interface.

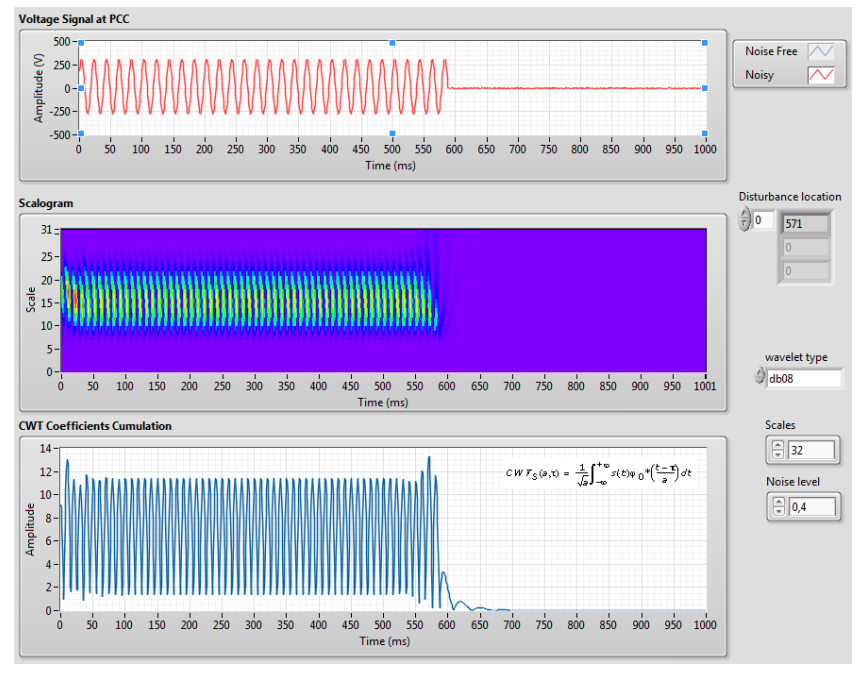

Figure 5. The developed software interface

\subsection{Wavelet Type and Threshold Value Selection}

In the study, different simulations and real-time applications were carried out to define the optimal wavelet type for islanding detection. The db8 was chosen as the main wavelet type because it shows the best properties of the characters in the islanding condition. It also reduces the computational time because it contains a few samples and a short wavelet type $[13,20]$.

In the proposed IDM, if the cumulation of CWT coefficients value obtained is less than the threshold value, it falls into the category of non-islanding condition. Otherwise, if the cumulation of CWT coefficients value is higher than the threshold value, it is the islanding condition.
In this study, the CWT coefficients cumulation is monitored in the micro-grid test system end is taken as a criterion for islanding condition detection. This cumulation considerable variations during grid supply disconnection (islanding condition). Differently, this variation of cumulation during non-islanding conditions (switching loads or short circuit faults) is insignificant. Using the simulations and real-time experimental studies, the optimal threshold value for the CWT cumulation was selected to be $(0.175)$. Scales specifies the number of scales of the dilated wavelet and scales. The scales factor was chosen as 10 for this method.

\section{Results}

The test system is operated under different grid and load conditions to test the performance of the developed IDM. Improved CWT-based IDM performance is evaluated for islanding and non-islanding conditions.

\subsection{Studied Islanding Conditions}

In the study, three different islanding conditions are examined. These cases are low power mismatch, high power mismatch and frequency changes under grid supply disconnection. Each examined situation is explained with details.

Case-1: The test system is operated with a low power mismatch for this case. Then, the grid supply disconnection has occurred. At the grid supply disconnection, the PV system output power is $1078 \mathrm{~W}$ and the power consumed by the load is $1100 \mathrm{~W}$. Fig. 6 shows the response of the proposed method as a result of an islanding condition (grid supply disconnection) in $572^{\text {nd }}$ seconds. The proposed IDM has detected the islanding condition very fast and high accuracy with the help of the determined threshold value and wavelet type. Although the change in the effective value of the voltage at PCC is within the limits, islanding detection could be performed using developed IDM. In these conditions, conventional passive methods cannot detect islanding. The islanding condition can be detected, even the worst-case scenario with the improved CWT-based IDM.

Case-2: Over/under voltage change detection is a significant issue for PV-based microgrids. When the effective voltage value at PCC exceeds the threshold value for the single-phase (uvp=198 V and ovp=242V) specified in IEEE 929-2000 standards, island mode operation must be detected in time. The PV-based microgrid is performed for a high-power mismatch condition. At the grid supply disconnection, the PV system output power is $768 \mathrm{~W}$ and the power consumed by the load is $990 \mathrm{~W}$. The proposed IDM can be analyzed with the developed software in LabVIEW. The islanding condition is shown in Fig. 7 starts at the $750^{\text {th }}$ millisecond, and this condition detected properly with the improved CWT-based IDM. 


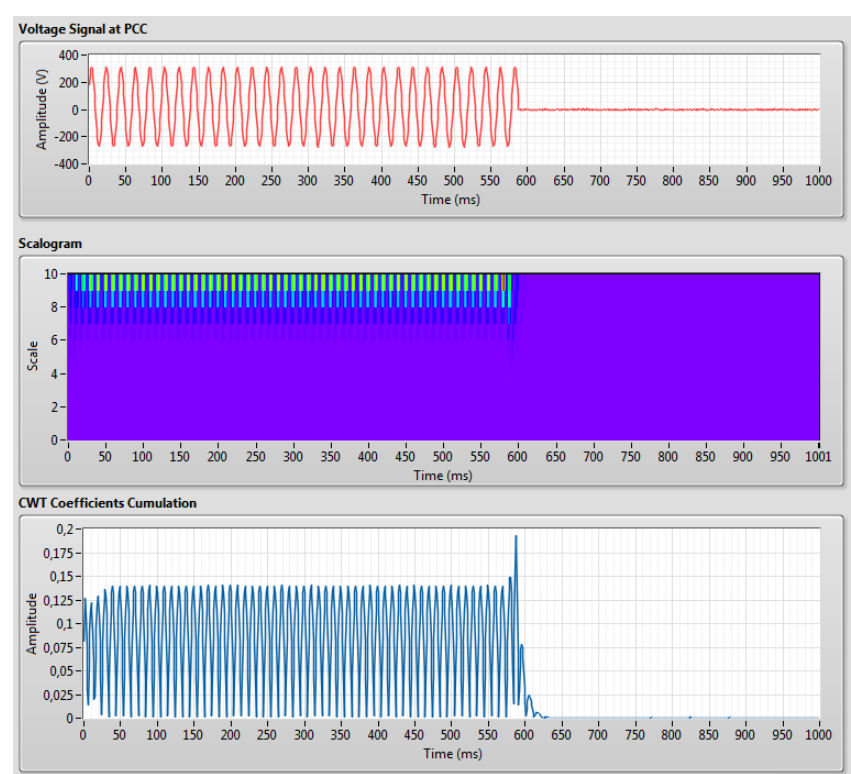

Figure 6. Case 1: Low power mismatch condition for developed IDM

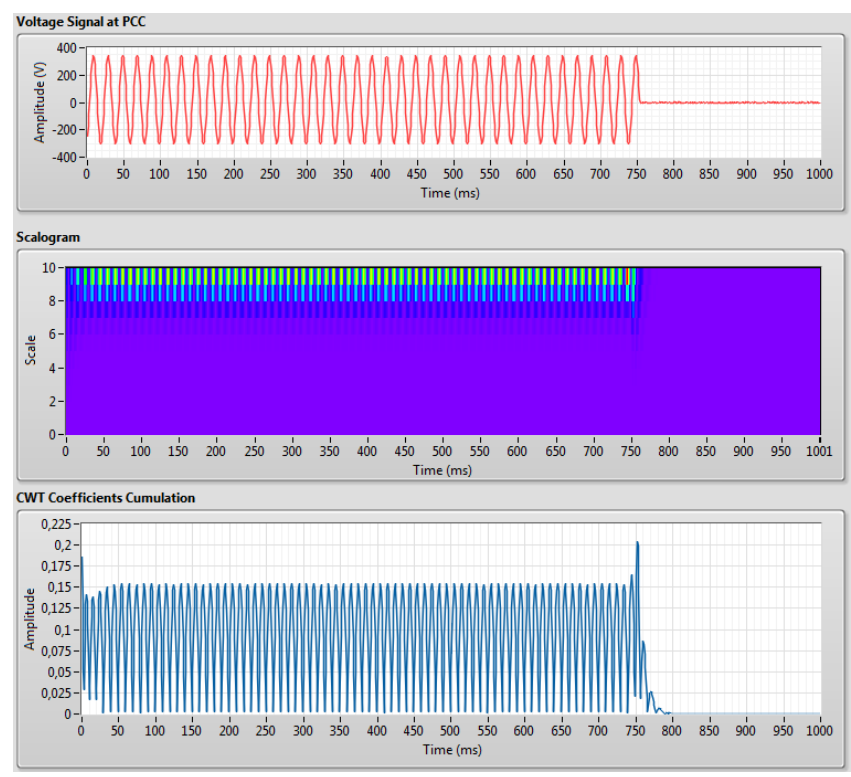

Figure 7. Case 2: High power mismatch condition for developed IDM

Case-3: Over/under frequency change detection is also another significant issue for PV-based microgrids. When the grid frequency at PCC exceeds the threshold values ( $u f p=49.8 \mathrm{~Hz}$ and ofp=50.2 Hz) specified in grid codes, islanding condition must be detected in time. Fig. 8 has shown this condition, and this disturbance starts at the 253rd millisecond. Cumulation value is higher than the specified threshold value of this condition. The proposed IDM has detected the islanding condition very fast and high accuracy for over frequency change events. Since there was not enough equipment to test the frequency change experimentally, the frequency was changed using the signal generator and the results were monitored.

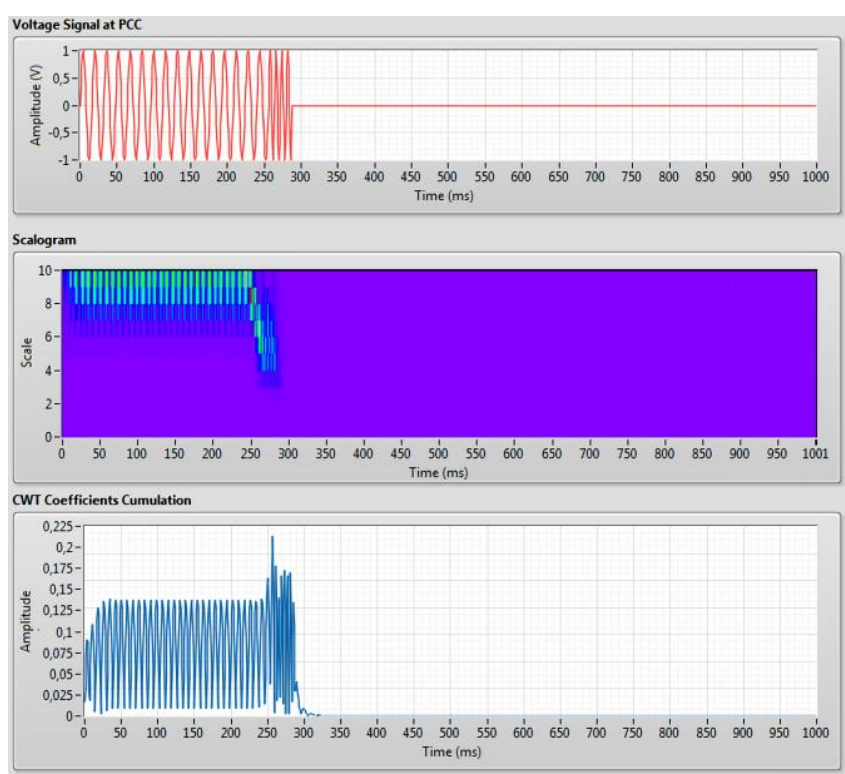

Figure 8. 3: Over/under frequency change condition for developed IDM

\subsection{Studied Non-Islanding Conditions}

An important criterion in evaluating island mode detection methods is that it can avoid false islanding detection for power quality disturbances. A real-time test scenario has been performed for short circuit failure (The conductor ends on the grid-side are shortcircuited for a short time with fuses.), which is the most common and important issue in the power system.

Case-4: Fig. 9 shows fault condition with 0.1-ohm resistance at the grid side, and it starts the $98^{\text {th }} \mathrm{ms}$. The peak value of the voltage signal under the moment of the fault has dropped to $192 \mathrm{~V}$. As a result of the fault on the grid side, voltage sag occurred at the PCC. The threshold value for the cumulation value was determined to be 0.175 . Cumulation value is under the specified threshold value for islanding condition. This problem, which is incorrectly detected as island mode in conventional methods, has been troubleshot with the proposed IDM.

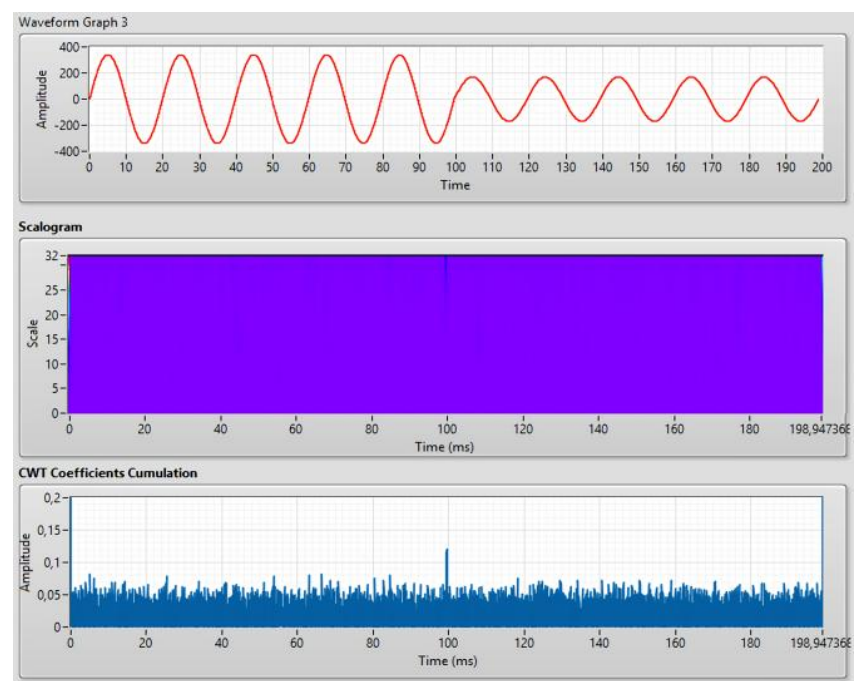


Figure 9. The response of developed IDM for a nonislanding condition

\section{Conclusion}

The processing time and the calculation load of the proposed method were measured by the program given in Fig. 10. It was seen that islanding detection was performed within the determined standards.

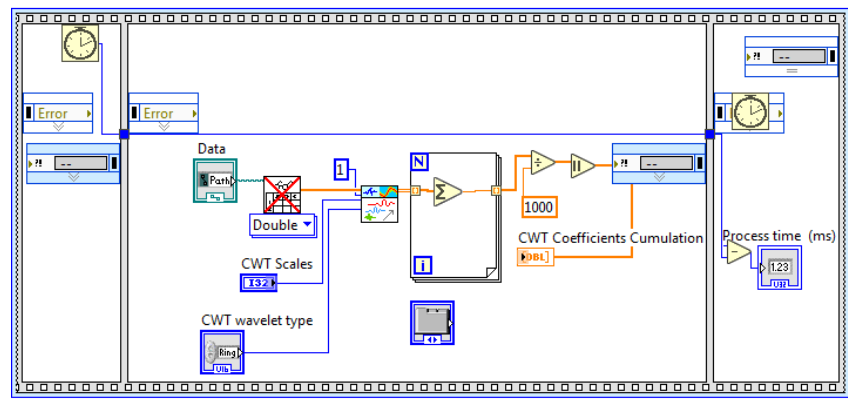

Figure 10. Calculation of processing time in the proposed method

In this study, a CWT-based real-time islanding detection method (IDM) in a PV-based microgrid is proposed. The proposed method was tested on a prototype microgrid test system constituted in the laboratory. Only the voltage signal at the PCC is used when performing this method and a set of discrete values is selected for the scales and shifts of continuous wavelets, and then the CWT method is applied. The studied WT-based automated IDM is compared with other methods in Table 1 . The compared methods have some drawbacks. In Ref [24] used a bigger sample size for detection. A combination of active frequency drift and wavelet entropy is used in Ref [21]. The detection time is higher than other methods. Ref [23] has a lot of scalability issues.

Table 1. Comparison of the studied CWT-based IDM with other methods

\begin{tabular}{cccc}
\hline Ref & Method & $\begin{array}{c}\text { Detection } \\
\text { time }\end{array}$ & NDZ \\
\hline$[21]$ & Hybrid method & $0.32 \mathrm{~s}$ & Almost zero \\
{$[22]$} & Passive method & $0.3 \mathrm{~s}$ & Almost zero \\
{$[23]$} & Hybrid method & $5 \mathrm{~ms}$ & Almost zero \\
{$[24]$} & Intelligent method & $0.18 \mathrm{~s}$ & Almost zero \\
----- & Proposed IDM & $\begin{array}{c}105-110 \\
\text { ms }\end{array}$ & Almost Zero \\
& & &
\end{tabular}

Computational load and measurement time loss are minimized by this method that will provide an advantage in real-time applications. The results show that the applied CWT-based IDM can detect different types of island modes. Besides, the islanding detection time of the proposed method varies between 105-110 $\mathrm{ms}$ in any island mode operations, and it is faster than the conventional detection methods. None detection zone (NDZ) is also almost zero in the proposed method.
Thus, the CWT-based islanding detection method provides both a reliable NDZ and a short detection time for real-time microgrid applications.

\section{References}

[1] Hassaine L, Olías E, Quintero J, Barrado A., "Power control for grid-connected applications based on the phase shifting of the inverter output voltage with respect to the grid voltage," Electrical Power and Energy Systems, 57., 250-260, 2014

[2] Eltawil ME, Zhao Z. "Grid-connected photovoltaic power systems: a technical and potential problemsa review." Renewable and Sustainable Energy Reviews, Vol. 14, 112-129, 2010.

[3] Lin, W. M., Wu, C. H., Lin, C. H., \& Cheng, F. S. "Detection and classification of multiple powerquality disturbances with wavelet multiclass SVM," IEEE Transactions on Power Delivery, Vol. 23(4), 2575-2582, 2008.

[4] Masoum, M. A. S., Jamali, S., \& Ghaffarzadeh, N. "Detection and classification of power quality disturbances using discrete wavelet transform and wavelet networks" IET Science, Measurement \& Technology, Vol. 4(4), 193-205, 2010.

[5] Bayrak, G. and Cebeci, M., "A communication-based islanding detection method for photovoltaic distributed generation systems" International Journal of Photoenergy, 2014.

[6] Kamel RM, Chaouachi A, Nagasaka K. "Enhancement of micro-grid performance during islanding mode using storage batteries and new fuzzy logic pitch angle controller," Energy Conversion and Management, Vol. 52: 2204-2216, 2011

[7] Shayeghi H, Sobhani B., "Zero NDZ assessment for anti-islanding protection using wavelet analysis and neuro-fuzzy system in an inverter-based distributed generation" Energy Conversion and Management Vol. 79, 616-625, 2014.

[8] Raza, S., Mokhlis, H., Arof, H., Laghari, J. A., and Wang, L., "Application of signal processing techniques for islanding detection of distributed generation in the distribution network," A review. Energy Conversion and Management, Vol. 96, 613$624,2015$.

[9] Jurado, F., \& Saenz, J. R., “Comparison between discrete STFT and wavelets for the analysis of power quality events." Electric Power Systems Research, Vol. 62(3), 183-190, 2002.

[10] Karegar, H. K., \& Sobhani, B., "Wavelet transform method for islanding detection of wind turbines." Renewable Energy, Vol. 38(1), 94-106, 2012.

[11] Latran M. B., Teke A., "A novel wavelet transform based voltage sag/swell detection algorithm," International Journal of Electrical Power \& Energy Systems, Vol.71, 131-139, 2015.

[12] Bayrak, G., "Wavelet transform-based fault detection method for hydrogen energy-based distributed generators." International Journal of Hydrogen Energy, Vol. 43(44), 20293-20308, 2018.

[13] Yilmaz, A., and Bayrak, G., "A real-time UWT-based intelligent fault detection method for PV-based 
microgrids." Electric Power Systems Research, 177, 105984. 2019.

[14] Zhu, Y., Yang, Q., Wu, J., Zheng, D., and Tian, Y. “A novel islanding detection method of distributed generator based on wavelet transform," International Conference on Electrical Machines and Systems, 2686-2688, 2008.

[15] Cohen, L., "Time-Frequency Analysis", PrenticeHall, Englewood Cliffs, 1995.

[16] National Instruments, LabVIEW advanced signal processing toolkit manual, 2014.

[17] Bayrak, G., \& Yilmaz, A., "Assessment of Power Quality Disturbances for Grid Integration of PV Power Plants," Sakarya University Journal of Science, Vol. 23(1), 1-1, 2019.

[18] Mishra, P. P., and Bhende, C. N., "Islanding detection using sparse S-transform in distributed generation systems," Electrical Engineering, Vol. 100(4), 23972406, 2018.

[19] Pigazo, A., Liserre, M., Mastromauro, R. A., Moreno, V. M., and Dell'Aquila, A., "Wavelet-based islanding detection in grid-connected PV systems," IEEE Transactions on Industrial Electronics, Vol. 56(11), 4445-4455, 2008.
[20] Yilmaz, A., Bayrak, G., "Assessment of Wavelet Types in DWT-based Power Quality Disturbance Detection Method, Academic Perspective Procedia, 2 (3), 1122-1130. DOI: 10.33793/acperpro.02.03.125.

[21] Shrivastava, S., Jain, S., Nema, R. K., \& Chaurasia, V., "Two-level islanding detection method for distributed generators in distribution networks", International Journal of Electrical Power \& Energy Systems, Vol. 87, 222-231, 2017.

[22] Abd-Elkader, A. G., Saleh, S. M., \& Eiteba, M. M., "A passive islanding detection strategy for multidistributed generations", International Journal of Electrical Power \& Energy Systems, Vol. 99, 146-155, 2018.

[23] Gupta, N., \& Garg, R., "Algorithm for islanding detection in photovoltaic generator network connected to the low-voltage grid", IET Generation, Transmission \& Distribution, Vol. 12(10), 22802287, 2018.

[24] Kong, X., Xu, X., Yan, Z., Chen, S., Yang, H., \& Han, D., "Deep learning hybrid method for islanding detection in distributed generation", Applied Energy, 210, 776-785, 2018. 